\title{
Biodiesel production by hydroesterification of microalgal biomass using heterogeneous catalyst
}

\author{
Yordanaka Reyes ${ }^{1}$, Gisel Chenard ${ }^{1}$, Donato Aranda $^{1}$, Cristiane Mesquita ${ }^{1}$, Mariana Fortes ${ }^{1^{*}}$, \\ Rafael João ${ }^{2}$, Leonardo Bacellar ${ }^{2}$ \\ ${ }^{1}$ Department of Chemical Engineering, Federal University of Rio de Janeiro (UFRJ), Rio de Janeiro, Brazil; \\ ${ }^{*}$ Corresponding Author: m.m.fortes@hotmail.com \\ ${ }^{2}$ Research and Development Center "Leopoldo Américo Miguez de Mello" (CENPES), Petrobras, Rio de Janeiro, Brasil.
}

Received 14 August 2012; revised 15 September 2012; accepted 27 September 2012

\begin{abstract}
This paper assesses the hydroesterification process for the production of Biodiesel from Monoraphidium contortum (MORF-1) microalgae biomass, as it is a sustainable alternative not only economically, but also environmentally and ecologically to replace petroleum diesel fuel. The Biodiesel studied in this work was obtained from fatty acid esterification, a product of microalgae and methanol biomass hydrolysis reaction. CBMM's (HY-340) niobium oxide powder was used as catalyst. The reactions were carried out in a properly closed autoclave reactor (batch), where the reagents were mixed under constant stirring at $500 \mathrm{rpm}$ for hydrolysis and esterification. The products generated were submitted to gas chromatography and oxidative stability analysis. The hydroesterification process showed itself to be a promising alternative to the conventional biodiesel production process (transesterification) as it favors the use of feedstocks with any acidity and moisture content and may be performed with acid catalyst, which favors high conversions in a small range of time (30 minutes).
\end{abstract}

Keywords: Biodiesel; Microalgae;

Hydroesterification; Biomass; Heterogeneous

\section{INTRODUCTION}

Microalgae are a potential feedstock for biofuel production, especially biodiesel, considering that since the 50s (first mass culture project on the rooftop at MIT, USA), and afterwards officially in the 70s (Aquatic Species Program: Biodiesel from algae, National Renewable Energy Laboratory-NREL. USA) and to this day, work has been constantly done in different countries (USA, Israel, Spain, New Zealand, Australia, Germany, The
Netherlands, etc.) to optimize the benefits and minimize the disadvantages associated to the production of biofuels by using microalgae as feedstock.

In this paper, the in situ Monoraphidium contortum (MORF-1) microalgae biomass biodiesel production by the hydroesterification method (hydrolysis followed by esterification) is studied. In addition, a chromatographic approach on the structural variations observed in the products formed is presented.

\section{MATERIALS AND METHODS}

\subsection{Feedstocks}

For the production of fatty acids (hydrolysis reaction), a species of freshwater microalgae biomass (Monoraphidium contortum) grown in a photo-bioreactor mounted in the Pilot GREENTEC/School of Chemistry/UFRJ area was used as feedstock; as hydrolasing agent, distilled water.

Biomass harvesting took place in the exponential growth phase by using flocculation, followed by centrifugation (Figure 1).

For the production of biodiesel (esterification reaction), the fatty acids of these microalgae, which were obtained as the biomass hydrolysis product, were used as feedstock. Absolute methyl alcohol, with $99.9 \%$ purity, supplied by TEDIA.

\subsection{Catalyst-Esterification}

The catalyst system used in the esterification reaction was niobium oxide powder (HY-340), which presents $90 \mathrm{~m}^{2} / \mathrm{g}$ surface area, given by CBMM (company dedicated to the extraction, processing, manufacturing and marketing products based on niobium).

\subsection{Equipment}

All the reactions were performed in batch reactor (Parr Instruments Inc.-4842 Model), autoclave type, made of 


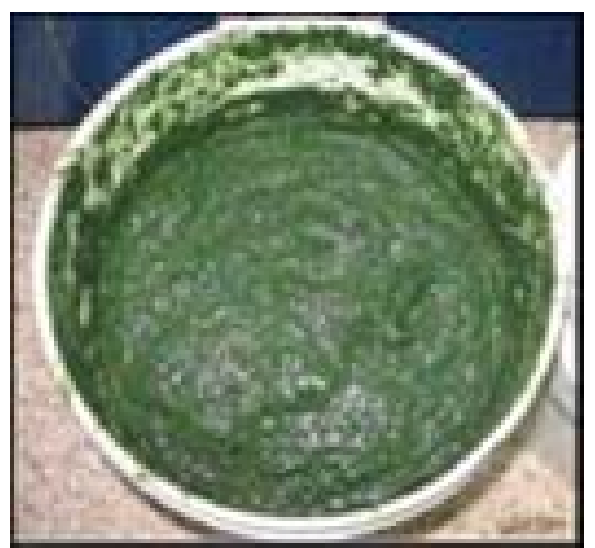

Figure 1. Paste resulting from centrifugation.

stainless steel, with $300 \mathrm{~mL}$ useful volume and $3.000 \mathrm{psi}$ maximum working pressure. Such reactor has a tube for withdrawing samples, as well as a stirring system and external heating mantle (Figure 2).

The operating conditions used in the reactions are shown in Table 1.

\subsection{Dry Weight of Microalgal Biomass}

To obtain the dry weight of the centrifuged microalgal biomass, watch-glasses were dried in an Icamo furnace at $105^{\circ} \mathrm{C}$ for 1 hour and cooled in a desiccator for 20 minutes. Cellulose nitrate filter paper with $0.8 \mu \mathrm{m}$ porosity, Stedium Sartorius Biotech brand, was used. The filter was pretreated in the furnace, as directed by the manufacturer. Then, the watch-glass with the paper filter were weighed in a Shimadzu balance, AY220 model, with the aid of tweezers, to avoid hand contact and weighing errors. The watch-glass with the filter was reserved in dessicator up to the moment of the vacuum filtration of the concentration, as shown in Figure 3. The analysis was performed in triplicate.

Filter paper was placed on the vacuum filter holder (a). Unit sealing (b). Addition of $10 \mathrm{~mL}$ concentrated medium into the filter (c). Addition of $40 \mathrm{~mL}$ MilliQ water for filtration (d). Addition of the filter with the filtered cells mass on the specific watch-glass (e) and furnace drying at $60^{\circ} \mathrm{C}$ until constant weight, for the dry weight attainment (f).

\subsection{Lipid Content Determination}

To perform the quantitative analysis of the lipids, $0.5 \mathrm{~g}$ or $500 \mathrm{mg}$ of dry weight cells of the studied microalgae were used, in triplicate. The mass of the sample used in the analysis was estimated from the dry mass of cells obtained as in the previous item.

To perform the extraction of lipids, the sample was submitted to two extraction stages. It was weighed in a centrifuge tube on a digital scale. With the aid of a pipette,

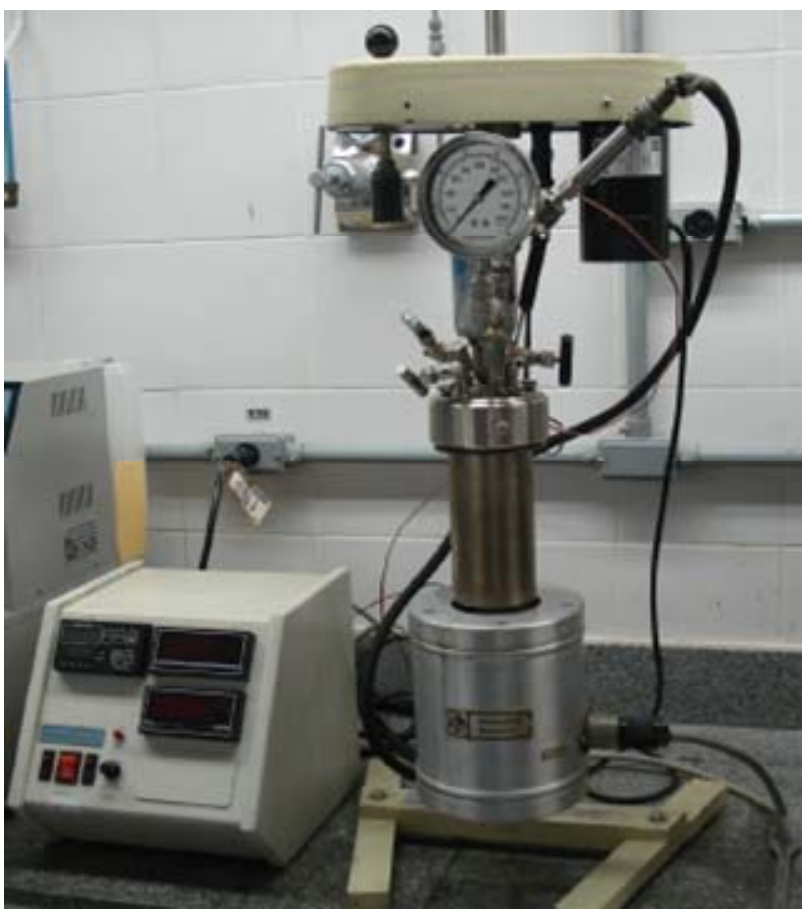

Figure 2. Autoclave reactor.

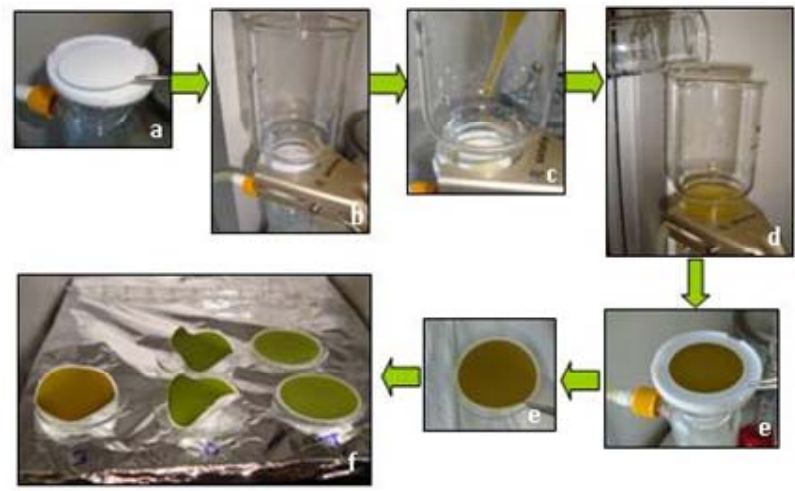

Figure 3. Simplified scheme to attain dry weight by vacuum filtration.

Table 1. Operating conditions.

\begin{tabular}{ccc}
\hline $\begin{array}{c}\text { Operating } \\
\text { conditions }\end{array}$ & Hydrolysis & Esterification \\
\hline $\begin{array}{c}\text { Temperature, }{ }^{\circ} \mathrm{C} \\
\text { Biomass } \\
\text { Concentration, \% } \\
\text { Catalyst } \\
\text { Concentration, \% }\end{array}$ & 250 & $150-200$ \\
Molar Ratio, mol & 5 & 10 \\
Reaction Time, h & 1 & $1.2-3.0$ \\
Agitation, rpm & 500 & 1 \\
\hline
\end{tabular}

$40 \mathrm{~mL}$ (2:1) of chloroform/methanol [1] were added. The tube was closed, agitated in vortex at $1400 \mathrm{rpm}$ for 
$20 \mathrm{~min}$, allowed to settle for $30 \mathrm{~min}$ and submitted to the a new agitation for $20 \mathrm{~min}$. Next, the sample was centrifuged at $3000 \mathrm{rpm}$ for $15 \mathrm{~min}$ at room temperature.

After the centrifugation, the liquid phase of the sample was collected in a beaker whose weight was previously known, which was taken to the furnace at $40^{\circ} \mathrm{C}$ for the evaporation of the solvents. The lipid quantitative was estimated by gravimetric analysis, relating the dry mass cells with the obtained lipid dry weight.

\subsection{Lipid Profile of the Microalgal Biomass}

To perform the lipid profile analysis, the sample obtained during the lipid content determination (as in theprevious item) was submitted to methanolysis reaction, according to the described methodology [2], with modifications.

$300 \mathrm{mg}$ of the lipid sample were used. Then, saponification was carried out with $1 \mathrm{~mL}$ of $\mathrm{KOH}-\mathrm{CH}_{3} \mathrm{OH}$ (alcoholic potash) saturated solution at $75^{\circ} \mathrm{C}$ for 10 minutes in Nova Ética's Water-bath. Afterwards, the sample was submitted to methanolysis with $2 \mathrm{ml}$ methanol with $5 \%$ $\mathrm{HCl}$ at $75^{\circ} \mathrm{C}$ for 10 minutes. Such stages were performed in closed flask to avoid evaporation. Subsequently, the phase containing the fatty acids was set apart with the addition of $2 \mathrm{ml}$ distilled water and $2 \mathrm{~mL}$ PA hexane. The upper phase of the hexane was collected with an automatic pipette and transferred to a flask that was placed in a furnace at $60^{\circ} \mathrm{C}$ for evaporation of the solvent and sample concentration.

The dried and reacted lipid sample had around $150 \mathrm{mg}$. $300 \mu \mathrm{L}$ P.A. heptane was added to it. The sample was manually shaken until it was homogeneous; then, it was eluted by gas chromatography (GC).

Analyses were performed in a Shimadzu GC, model 2014 , with Split injector at $250^{\circ} \mathrm{C}$, with a $20 \mathrm{~mL} / \mathrm{min}$ flow, FID detector at $250^{\circ} \mathrm{C}$ and isothermal oven at $200^{\circ} \mathrm{C}$. A Quadrex Carbowax $20 \mathrm{M}$ capillary column, with polyethylene glycol stationary phase and $30 \mathrm{~m} \times$ $0.32 \mathrm{~mm} \times 0.25 \mu \mathrm{m}$ dimensions was used.

The lipid profile was identified by comparison with the standard sample and determined by the integrated areas of each peak.

\subsection{Acids Composition Determination-Hydrolysis}

The products obtained by hydrolysis reactions were analyzed according to the fatty acids composition of the sample. To identify the fatty acids, different fatty acid patterns were injected to identify the peaks areas and retention times. Heptadenoic acid was used as internal standard.

This method was developed, with the purpose of predicting both qualitatively and quantitatively, by observing the chromatograms, how many triacylglycerides can be transformed into fatty acid and thus, observe the performance of the reaction in the suggested conditions.

The dilution of the sample (hydrolyzed product) in heptadenoic acid at a $0.05: 1(\mathrm{~m} / \mathrm{m})$ ratio was necessary. Then $1 \mu \mathrm{L}$ of the sample was injected into the Shimadzu chromatograph, model GC-2010, with split/splitless injector, flame ionization detector (FID), Quadrex Carbowax column $(30 \mathrm{~m} \times 0.32 \mathrm{~mm} \times 0.25 \mu \mathrm{m})$, under the following conditions : $200^{\circ} \mathrm{C}$ isothermal, Injector: $250^{\circ} \mathrm{C}$, Detector: $250^{\circ} \mathrm{C}$, Carrier gas pressure: $1.9 \mathrm{~mL} / \mathrm{min}$. Analyses were performed for 1 hour.

\subsection{Biodiesel Characterization}

The final product of the hydroesterification process was characterized according to ANP's (Brazil's oil regulator) No. 42 resolution, "Specification for B100 biodiesel".

\section{Percentage Determination of FAME (Fatty Acid Methyl Esters-Gas Chromatography (GC-FID)}

The reaction products obtained by hydroesterification reactions (hydrolysis and esterification) were quantified by gas chromatography (GC) according to the content of fatty acid esters. In this methodology it is possible to identify both qualitatively and quantitatively the esters present in biodiesel. Methyl heptadecanoate was used as internal standard.

The dilution of $0.25 \mathrm{~g}$ of the sample (biodiesel) in $5 \mathrm{ml}$ methyl heptadecanoate solution was necessary. Next, 1 $\mu \mathrm{L}$ of the sample was injected into the Shimadzu chromatograph, model GC-2014 with split/splitless injector, Flame ionization detector (FID), Quadrex Carbowax $20 \mathrm{M}$ capillary column $(30 \mathrm{~m} \times 0.32 \mathrm{~mm} \times 0.25 \mu \mathrm{m})$, with the following conditions: $200^{\circ} \mathrm{C}$ isothermal, Injector: $250^{\circ} \mathrm{C}$, Detector: $250^{\circ} \mathrm{C}$, Gas carrier: Helium or Hydrogen, $30 \mathrm{kPa}$ to $100 \mathrm{kPa}$ pressure. $1 \mathrm{~mL}$ to $2 \mathrm{~mL}$ flow, Total time of analysis: about $25 \mathrm{~min}$. A computer, equipped with the GC SOLUTION software was used for the capture and analysis of the chromatograms.

\section{RESULTS AND DISCUSSION}

\subsection{Lipid Profile}

The lipid profile of the studied microalgal biomass, obtained by the esters analysis in the GC is shown in the chromatogram of Figure 4.

According to these data, the studied species showed the following fatty acids distribution: SAFA (saturated fatty acid) $>$ PUFA (polyunsaturated fatty acid) $>$ MUFA (monounsaturated fatty acid) content. The higher values refer to SAFAs, being C16:0 (palmitic acid) and C11:0 (undecanoic acid) the ones that stand out.

Concerning the PUFAs, high content of C18:3 (lino lenic) was observed. The second highest content of 

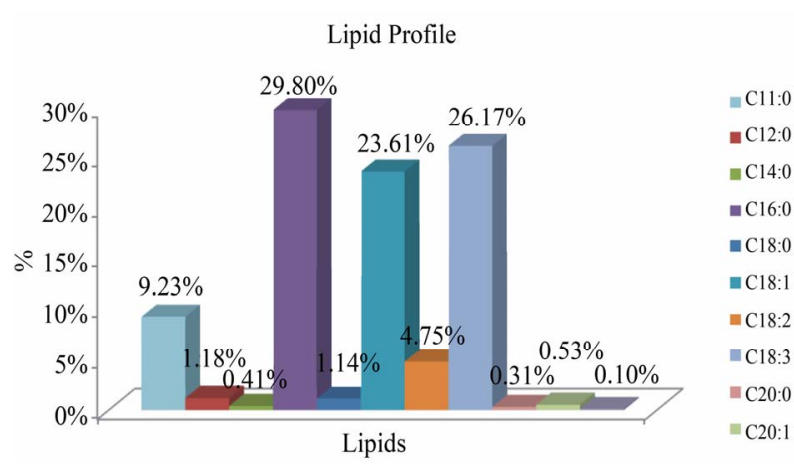

Figure 4. Chromatogram-Lipid profile of the microalgal biomass. Identification: C11:0 (9.23\%), C12:0 (1.18\%), C14:0 (0.41\%), C16:0 (29.80\%), C18:0 (1.14\%), C18:1 (23.61\%), C18:2 (4.75\%), C18:3 (26.17\%), C20:0 (0.31\%), C20:1 $(0.53 \%), \mathrm{C} 22: 0(0.10 \%)$.

PUFA was the linoleic (C18:2) one.

As for the MUFAs, the oleic acid (C18:1) stands out.

The studied microalgal biomass had high levels of SAFA, mainly palmitic acid (C16:0) with concentrations near $30 \%$, a feature similar to palm oil and tallow, which are high in saturated fat.

On the other hand, the species had a high concentration of monounsaturated fats, mainly represented by C18:1 (oleic acid) $\approx 23 \%$, highly concentrated in tallow and mainly in olive oil.

C18:3 (linolenic acid) was also identified in high amounts $(\approx 26 \%)$, as well as C18:2 (linoleic acid) in $(\approx$ $5 \%$ ); they appear at higher concentrations in soy.

These results were consistent with those found in previous papers, in which palmitic acid was determined as prevalent in most of the microalgae species grown in freshwater [3-5].

The Scenedesmus obliquus microalgae showed palmitic acid (C16:0) concentration-between $35.86 \%$ and $43.06 \%$ [6-7].

This amount of saturated fatty acids in the microalgae was also observed by [2], when he studied the lipid profile of the microalgae Chlorella vulgaris, Scenedesmus and Botryococcus sp braunni. In that study, the researchers achieved 36.3\% palmitic acid for Scenedesmus sp.

\subsection{In Situ Hydrolysis of the Microalgal Biomass}

To perform the in situ hydrolysis of the microalgal biomass, 300g of the centrifuged sample, consisting of $5 \%$ biomass and $95 \%$ water, was used. The sample was hydrolized at $250^{\circ} \mathrm{C}$ temperature for one hour reaction. Since the lipid content of such biomass is around $27.79 \%$ (dry weight), a definitive oil phase was not observed as expected (Figure 5). Thus, it was necessary to perform a hexane extraction to collect the fatty acids resulting from hydrolysis. After extracting and drying in a furnace at

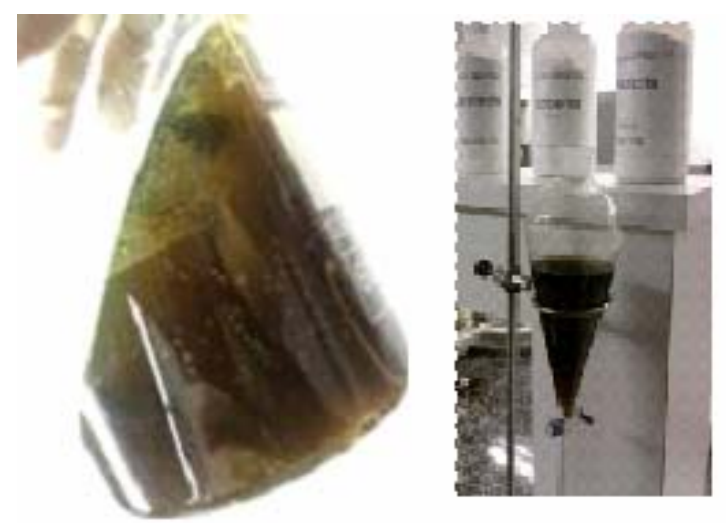

Figure 5. Product of the microalgal biomass hydrolysis.

$60^{\circ} \mathrm{C}$, a sample of $60 \mathrm{mg}$ (fatty acids mixture) was obtained in each hydrolysis. Five hydrolysis experiments were carried out, until a significant amount of sample was obtained to allow the esterification stage.

Figure 6 shows the chromatogram of the fatty acids profile present in the hydrolysis product. Such result confirms the in situ occurrence of microalgal biomass hydrolysis.

This is a very interesting result; it represents a signifycant economic benefit, considering the possibility of producing biodiesel directly from wet biomass, eliminating the lyophilization and oil extraction processes.

\subsection{Esterification-The Generation of Methyl Esters}

For the esterification reaction, niobium oxide powder was used as catalyst.

The reactions were carried out by using excess alcohol and the mixture of fatty acids resulting from the hydrolysis process, $\mathrm{MM}=256.42 \mathrm{~g} / \mathrm{mol}$, according to the following protocol: alcohol molar ratio: 30:1 fatty acid, $200^{\circ} \mathrm{C}, 10 \%$ catalyst, 1 hour reaction and $500 \mathrm{rpm}$ agitation, for as observed by [8], above such rotations, no significant conversions were found, despite knowing that $80 \%$ of the vegetable oil is converted into biodiesel in the first 10 to 20 minutes contact among the reactants $[8,9] .60$ minutes was the response time established for all the experiments since, as described by [8], times over 20 minutes did not cause significant increases in the reaction conversion; however, they may favor the observation of reaction kinetics as a whole, as they are scarcely known reactions.

In the esterification reaction there is no glycerol formation, so the product was directly submitted to drying to remove the residual water and methanol. The catalyst could be recovered by filtration.

The final product of the reaction was submitted to chromatographic analyses so as to identify the product formed in the reaction. The results confirm the occur- 


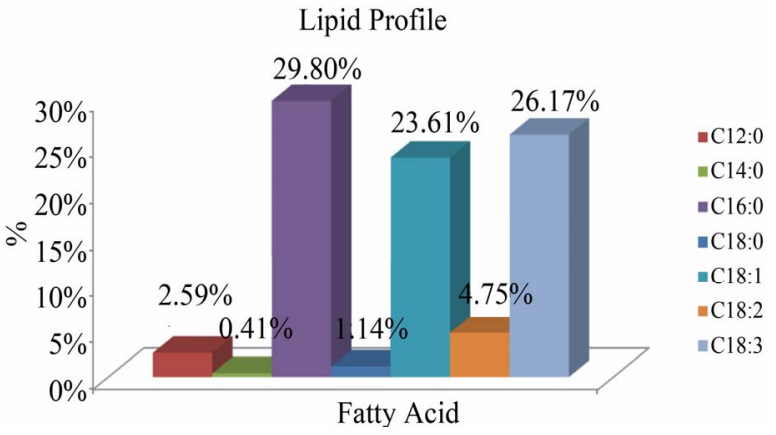

Figure 6. Chromatogram-Fatty acids obtained by in situ microalgal biomass hydrolysis. Identification: C12:0 (2.59\%), C14: 0 (0.88\%), C16: 0 (39.32\%), C18: 0 (8.49\%), C18:1 (29.35\%), C18:2 (4.36\%), C18:3 (14.99\%).

rence of the fatty acids esterification process. The behavior follows the same pattern previously discussed in the microalgal biomass lipid profile determination and can be seen in Figure 7.

It is important to observe that the total ester percentage was of $94.27 \%$. Similar results have been found by [9], studying the production of fatty esters in the presence of methanol with Chlorella vulgaris microalgae by using acidic transesterification process. The lipids rate of conversion into methyl esters obtained in this study was, in average, of $91.7 \%$.

\subsection{Biodiesel Characterization}

The methyl esters obtained by using the proposed technology were characterized in relation to some distinctive parameters required by ANP. While still preliminary, they give an idea of the microalgae biodiesel quality. However, there is still a long way to go in the process of optimization.

It is known that among vegetable oils, fatty acid composition varies and so do their physicochemical properties (for instance, the oxidative stability). The same occurs with the oil extracted from different microalgae species and also with the same species grown under different conditions.

Biodiesel and biodiesel blends are exposed to air, acids begin to form, which are transferred to a conductivity cell containing deionized water. Once the acid concentration in the water is high enough, the conductivity undergoes a rapid increase that is called the induction period.

The oxidative stability of the sample obtained in this experiment was around 4.77 hours (Figure 8), according to the EN14112 trial performed in the Rancimat device. This result is consistent with the previous ones, in other words, high content of saturated fatty acids in the feedstock; therefore, a high content of saturated esters in the biodiesel composition - an aspect earlier confirmed by chromatography. The value obtained is not very different

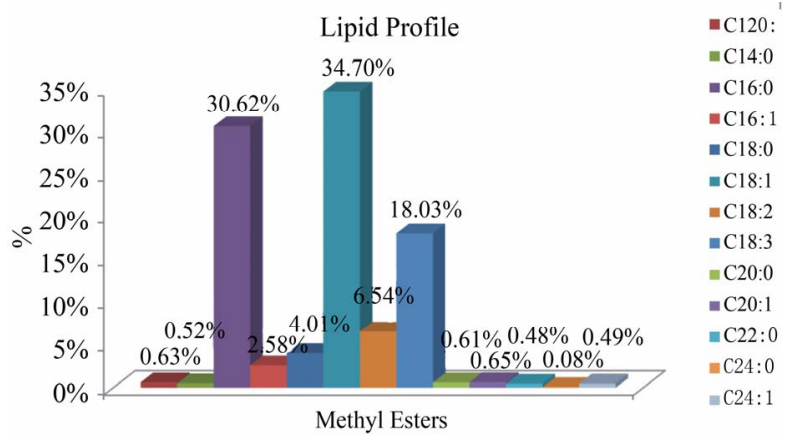

Figure 7. Chromatogram-Methyl esters resulting from the microalgal biomass hydroesterification. Identification: C12:0 (0.63\%), C14:0 (0.52\%), C16:0 (30.62\%), C16:1 (2.58\%), C18:0 (4.01), C18:1 (34.70\%), C18:2 (6.54\%), C18:3 (18.03\%), C20:0 (0.61\%), C20:1 (0.65\%) C22:0 (0.48\%), C24:0 (0.08\%), $\mathrm{C} 24: 1(0.49 \%)$.

\section{Oxidative Stability}

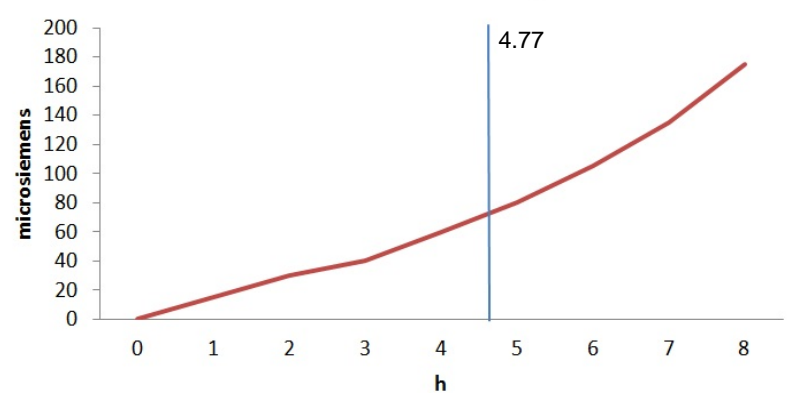

Figure 8. Oxidative stability of the studied microalgal biomass methyl esters.

from the esters profile normally observed in the biodiesel derived from conventional oleaginous (6 hours time for the standard soy biodiesel).

As already widely discussed, palmitic acid, oleic acid and linolenic acid were the dominant constituents in the lipid composition of the studied microalgal biomass. These medium chain fatty acids (C16 and C18) are considered ideal for producing high quality biodiesel, as mentioned in [10-11]'s work and are the most direct and accurate parameter to assess microalgae's potential as feedstock for the production of biodiesel, since not all of the soluble compounds in organic solvents used in extraction may be converted into biodiesel.

There are other parameters that are considered very important when studying the quality of biodiesel, such as the amount of mono-, di- and tri-glycerides present in biodiesel. These data allow the observation of the reaction performance in the assessed reaction conditions evaluated. The values obtained in this study are presented in Table 2 . They are under the maximum limits required by ANP, a fact undoubtedly associated to the obtainment of biodiesel from free fatty acids. Although these results are still embryonic, they hold an enormous promise concerning 
Table 2. Preliminary characterization of the biodiesel made from Monoraphidium contortum (MORF-1) microalgae.

\begin{tabular}{|c|c|c|c|}
\hline Characteristics & Methods & $\begin{array}{l}\text { Specification } \\
\text { for B100 }\end{array}$ & $\begin{array}{c}\text { Microalgae } \\
\text { Biodiesel }\end{array}$ \\
\hline $\begin{array}{c}\text { Ester } \\
\text { content, } \\
\% \mathrm{~m} / \mathrm{m}\end{array}$ & EN 14103 & Report & 94.27 \\
\hline $\begin{array}{l}\text { Free Glycerin, } \% \\
\mathrm{~m} / \mathrm{m}\end{array}$ & $\begin{array}{c}\text { ASTM-D } 6584 \\
\text { EN } 14105 \\
\text { EN } 14106\end{array}$ & 0.02 max. & 0.00152 \\
\hline $\begin{array}{c}\text { Total Glycerin, } \\
\% \mathrm{~m} / \mathrm{m}\end{array}$ & $\begin{array}{l}\text { ASTM-D } 6584 \\
\text { EN } 14105\end{array}$ & 0.38 max. & 0.0106 \\
\hline $\begin{array}{c}\text { Monoglycerides, } \\
\% \mathrm{~m} / \mathrm{m}\end{array}$ & $\begin{array}{c}\text { ASTM-D } 6584 \\
\text { EN } 14105\end{array}$ & Report & 0.0310 \\
\hline $\begin{array}{l}\text { Diglycerides, } \\
\% \mathrm{~m} / \mathrm{m}\end{array}$ & $\begin{array}{l}\text { ASTM-D } 6584 \\
\text { EN } 14105\end{array}$ & Report & 0.0000 \\
\hline $\begin{array}{c}\text { Triglycerides, } \\
\% \mathrm{~m} / \mathrm{m}\end{array}$ & $\begin{array}{l}\text { ASTM-D } 6584 \\
\text { EN } 14105\end{array}$ & Report & 0.0097 \\
\hline $\begin{array}{l}\text { Oxidation Stabil- } \\
\text { ity to } 110^{\circ} \mathrm{C}, \mathrm{h}\end{array}$ & EN 14112 & $6 \mathrm{~h}$ & 4.77 \\
\hline
\end{tabular}

microalgae's potential as a future source of biofuel.

\section{CONCLUSIONS}

1) It is possible to obtain fatty acids through in situ microalgal biomass hydrolysis.

2) The analysis of the fatty acids in the studied microalgae displayed saturated fatty acids predominance, which was considered ideal for producing high quality biodiesel.

3) By using the proposed technology, the characteristics of the biodiesel obtained from the studied microalgal biomass are similar to the biodiesel produced from conventional feedstock, such as palm oil, soy, etc.

4) The results of this study confirm that there is still much to study regarding the variables involved in the hydroesterification technology, suggested to produce biodiesel by the in situ processing of microalgal biomass.

\section{REFERENCES}

[1] Folch, M., Lees, M. and Stanley, G. (1957) A simple method for the isolation and purification of total lipids from animal tissues. The Journal of Biological Chemistry,
226, 497-509.

[2] Yoo, C., Jun, S. and Lee, J. (2010) Selection of microalgae for lipid production under high levels carbon dioxide. Bioresource Technology, 101, 71-74. doi:10.1016/2009.03.030

[3] Colla, L., Bertolini, T. and Costa, J. (2004) Fatty acids profile of Spirulina platensis grown under different temperatures and nitrogen concentrations. Zeitschrift fur Naturforschung, 59, 55-59.

[4] Deshnium, P., Paithoonrangsarid, K. and Suphatrakul, A. (2000) Temperature-independent and dependent expression of desaturase genes in filamentous cyanobacterium Spirulina. FEMS Microbiology Letters, 184, 207-213. doi:10.1111/1574-6968.2000.09015

[5] Olguín, E., Galicia, S. and Angulo-Guerrero, O. (2001) The effect of low light flux and nitrogen deficiency on the chemical composition of Spirulina sp., Bioresource Technology, 77, 19-24. doi:10.1016/0960-8524(00)00142-5

[6] Makulla, A. (2000) Fatty acid composition of Scenedesmus obliquus: Correlation to dilution rates. Limnology, 30, 162-168. doi:10.1016/0075-9511(00)80011-0

[7] Willis, M., Lencki, R. and Marangoni, A. (1998) Lipid modification strategies in the production of nutritionally functional fats and oils. Criticals Reviews in Food Science and Nutrition, 38, 639-674. doi:10.1080/10408699891274336

[8] Rodrigues, B., Constantino, A. and Carvalho, L. (2005) Palm fatty acid esterification using heterogeneous catalysts. 13 Brazilian Congress of Catalysis, 4, 1-4.

[9] Veljkovic, V.B., Lakicevic, S.H., Stamenkovic, O.S., Todorovic, Z.B. and Lazic, M.L. (2006) Biodiesel production from tobacco (Nicotiana tabacum L.) seed oil with a high content of free fatty acids. Fuel, 85, 2671-2675. doi:10.1016/2006.04.015

[10] Marchetti, J. and Miguel, V. (2007) Heterogeneous esterifications of oil with high amount of free fatty acids. Fuel, 86, 906-910. doi:10.1016/2006.09.006

[11] Furuta, S., Matsuhashi, H. and Arata, K. (2004) Biodiesel fuel production with solid superacid catalysis fixed bed reactor under atmospheric pressure. Catalysis Communications, 5, 721-723. doi:10.1016/2004.09.001 